УДК 159,99

DOI https://doi.org/10.23947/2658-7165-2021-4-1-62-76

\title{
Психодогические предикторы адаптации образовательных мигрантов к трудной жизненной ситуации
}

\author{
Виктор А. Клименко ${ }^{1}$, Анастасия В. Гришина ${ }^{2 *}$ \\ ${ }^{1}$ Национадьный исследовательский Томский государственный университет, \\ Томск, Российская Федерация \\ ${ }^{2}$ Донской государственный технический университет, г. Ростов-на-Дону, \\ Российская Федерация \\ *E-mail: avgrishina.donstu@gmail.com \\ * ORCID: https://orcid.org/0000-0003-2202-2588
}

\begin{abstract}
Аннотация
Во ВвеАении раскрывается понятие образовательной миграции как трудной Жизненной ситуации, переживаемой студентами. Миграционные потоки студентов растут с кажАЫм гоАом во всем мире, а значит изучение психологических особенностей этой группы молодежи, а также сложностей, с которыми они сталкиваются, является чрезвычайно актуальным Аля психологической науки. Сложившаяся во всем мире ситуация пандемии и вынужАенной самоизоляции привела к еще более серьезным психологическим послеАствиям Аля образовательных мигрантов, веАь многие из них не могли вернуться на родину, либо приехать к месту учебы, что повышало тревожность за свое будущее и карьеру, за невозможность помочь своим близким и т. А. ПровеАенное эмпирическое исследование бы^о посвящено изучению с^ожных жизненных ситуаций, их типов и распространенности на разных группах образовательных мигрантов в периол пандемии COVID-19. Новизна исслеАования заключается в изучении сложных жизненных ситуаций образовательных мигрантов. В разделе «Методыл описана эмпирическая база исследования. Её составили 380 человек - студенты высших учебных заведений Екатеринбурга и Томска в возрасте 18-22 с разным миграционным опытом. ИсслеАование провоАилось с помощью авторской анкеты, в которую вошли вопросы о переживании наиболее частовстречающихся сложных жизненных ситуаций Аля образовательных мигрантов этих регионов: заболевания коронавирусом, переживания о зАоровье близких, несостоявшаяся поезАка (фиксирующая сложности передвижения), сложности с учебой, проблемы в ^ичной жизни, бытовые сложности. РазАел «Результаты» показывает, что приналмежность к группе «образовательных мигрантов» не влияет ОАнозначно на специфику восприятия с^ожных жизненных ситуаций молоАыми ^юАьми, их частоту и типичность переживания. В разАеле «ОбсужАение результатов"
\end{abstract}


полученные Аанные сравниваются с Аанными зарубежных исследователей, изучающих особенности аАаптации образовательных мигрантов к новой образовательной и социально-психологической среАе. РазАеА «ВывоАы» гАасит, что самыми «попу^ярными» и значимыми с точки зрения френомена «сложных жизненных ситуаций» Аля респонАентов оказались сложности с учебой и переживания о зАоровье близких.

\title{
КАючевые слова
}

образовательная миграция, сложная жизненная ситуация, мичностные ресурсы, алаптация, Covid-19

\section{Для цитирования}

Клименко В. А., Гришина А. В. Психологические предикторы адаптации образовательных мигрантов к трудной жизненной ситуации // Инновационная наука: психология, педагогика, дефектология. 2021. Т. 4, № 1. С. 62-76. doi: https://doi.org/10.23947/2658-7165-2021-4-1-62-76

\section{Psychological predictors of adaptation of educational migrants to a difficult life situation}

\author{
Victor A. Klimenko ${ }^{1}$, Anastasia V. Grishina ${ }^{2 *}$ \\ ${ }^{1}$ Tomsk State University, Tomsk, Russian Federation \\ ${ }^{2}$ Don State Technical University, Rostov-on-Don, Russian Federation \\ *E-mail: avgrishina.donstu@gmail.com \\ * ORCID: https://orcid.org/0000-0003-2202-2588
}

\begin{abstract}
The introduction reveals the concept of educational migration as a difficult life situation experienced by students. The migration flows of students are growing every year worldwide, which means that the study of the psychological characteristics of this group of young people and the difficulties they face are extremely relevant for psychological science. The current situation of a pandemic and forced self-isolation throughout the world led to even more serious psychological consequences for educational migrants, because many of them could not return to their homeland or come to their places of study, which increased anxiety for their future and career, for the inability to help their loved ones, etc. The conducted empirical research was devoted to the study of difficult life situations, their types, and prevalence in different groups of educational migrants during the COVID-19 pandemic. The novelty of the research lies in the study of difficult life situations of educational migrants. The section "Methods" describes the empirical basis of the study. It was made up of 380 people - students of higher
\end{abstract}


educational institutions of Yekaterinburg and Tomsk at the age of 18-22 with different migration experiences. The study was carried out using the author's questionnaire, which included questions about the experience of the most common difficult life situations for educational migrants in these regions: coronavirus disease, worries about the health of loved ones, a failed trip (fixing the difficulties of movement), difficulties with studies, problems in personal life, everyday difficulties. The section "Results" shows that belonging to the group of "educational migrants" does not unambiguously affect the specificity of perception of difficult life situations by young people, their frequency, and typicality of experience. In the section "Discussion of the results" the obtained data are compared with the data of foreign researchers studying the features of adaptation of educational migrants to the new educational and socio-psychological environment. The "Conclusions" section states that the most "popular" and significant from the point of view of the phenomenon of "difficult life situations" for the respondents were difficulties with learning and worries about the health of friends and family.

\section{Keywords}

educational migration, difficult life situation, personal resources, adaptation, Covid-19

\section{For citation}

Klimenko, V.A., Grishina, A. V. (2021). Psychological predictors of adaptation of educational migrants to a difficult life situation. Innovative Science: psychology, pedagogy, defectology, 4(1), 62-76. doi: https://doi.org/10.23947/2658-7165-2021-4-1-62-76

\section{Введение}

В последние годы интерес к проблеме личностных ресурсов и к вопросам выявления предикторов их актуализации неуклонно растет в условиях глобального ускорения жизни и нарастающего уровня стресса. Это обуславливает актуальность темы.

Одной из наиболее подверженных стрессу и происходящим изменениям оказывается молодежь студенческого возраста, еще только начавшая самостоятельную жизнь, испытывающая типичные для возрастного периода трудности адаптации, совладания со сложными жизненными ситуациями, развития самоорганизации и самостоятельности. Причем наиболее активной и развивающейся группой современной молодежи считается категория образоватедьных мигрантов - молодых людей, переезжающих в другие регионы и страны ради получения высшего образования. Эта студенческая группа в целом обладает более высоким адаптационным потенциалом, однако, и они сталкиваются с серьезными сложностями в процессе интеграции в другую социальную, а иногда, и этническую среду. 
Ситуация миграции, вне зависимости от готовности к ней конкретной дичности, рассматривается как трудная жизненная ситуация, задействующая значительное количество личностных ресурсов и требующая от мигранта развития принципиально новых социально-психологических компетенций.

Исследования сложных жизненных ситуаций традиционно проводятся, как в психологии, так и в других социальных науках: У. Томас (1928); С. А. Рубинштейн (1935), Курт Левин (1946), Д. Магнуссон (1983); Л. И. Анцыферова (1994); А. Г. Дикая (1996), К. А. Абульханова (1999); Е. А. Петрова (2004); Е. В. Битюцкая (2007); А. Росс, Р. Нисбетт (2009); Н. Б. Парфенова (2009); Н. В. Гришина (2012); О. В. Александрова, И. Б. Дерманова (2017).

Проблемами образовательных мигрантов в России занимаются, традиционно обращаясь к исследованию иностранных студентов, их дичностных особенностей, проблем адаптации или, наоборот, миграционных настроений российской обучающейся молодежи: Д. Н. Митин, Е. М. Покровская, Е. Н. Шпет, Е. А. Трофимов, Т. И. Трофимова, В. В. Константинов, Н. И. Леонов, Ф. Х. Хасан (Митин, 2010; Покровская, Смольникова, Ларионова, 2014; Шпет, 2015; Трофимов, Трофимова, 2017; Леонов, Хасан, 2019). Однако вопрос об исследовании психологических предикторов успешной интеграции образовательных мигрантов в принимающее общество практически открыт.

Под образовательной миграцией понимают перемещение людей с целью получения образования. В нашей стране группа образовательных мигрантов явдяется одной из самых развивающихся, как в количественном, так и в качественном плане. Ее динамика может быть проилдюстрирована статистическими данными и объяснена существующими трендами развития образовательной, миграционной и научной подитики. Интенсификации процессов образовательной миграции способствует целый ряд причин (Апанович, 2015; Трофимов, Трофимова, 2017; Шпет, 2015; Игнатовский, Штро, 2019):

- Интернационализация образования, развившаяся с одной стороны вследствие общих глобализационных процессов, а с другой,-ставшая, благодаря Проекту 5/100, в российской высшей школе одним из показателей эффективности и рейтингования вуза;

- Появление тренда на позиционирование университетов через раздичные рейтинги, многие из которых учитывают в качестве одного из показателей расчета - количество обучающихся из других стран и регионов;

- Научно-технический прогресс, в частности развитие информационных пространств и платформ, Интернет-сетей и диджитализации;

- Рост популярности массовых онлайн-курсов (МООК), особенно заметный в условиях пандемии и повсеместного введения элементов дистанционного образования в практику высшей школы;

- Изменение отношения к преемственности специализации и научной школы, 
в том числе в рамках двухуровневой системы высшего образования, вследствие чего после окончания первой ступени обучения все больше студентов меняют не только учебное заведение (которое тоже считает рост числа привлеченных образовательных мигрантов на каждый уровень обучения положительным показателем), но и даже свою образовательную траекторию;

- Появление «рынка образовательных услуг», которое сложно представить для советского и постсоветского периода развития образования (Трофимов, Трофимова, 2017).

В результате в последние годы наблюдается стремительный рост образовательной миграции. В частности, Россия, с точки зрения международной образовательной миграции выступая в качестве страны-реципиента, ежегодно принимает по 300 тысяч студентов на обучение в высших учебных заведениях, и каждый год этот показатель растет и, по плану, удвоится в ближайшие 5 лет (по данным федерадьного проекта «Экспорт образования», проектного офиса «5-100», Министерства науки и высшего образования).

К основным характеристикам образовательной миграции относят:

- Носит временный характер и ограничена периодом получения образования или прохождения конкретного учебного курса (Рязанцев, 2010);

- Чаще всего относится к определенной возрастной группе;

- Предполагает перемещение в другой регион / страну;

- В основном добровольна (Трофимов, Трофимова, 2017).

Основной возрастной группой образовательных мигрантов является категория 17-22 яет: когда, закончив школу, юноши и девушки поступают в высшие учебные заведения, вследствие чего - перемещаются по направлению к выбранному учебному заведению. И здесь молодые люди вне зависимости от своей готовности к этим изменениям сталкиваются с специфичной трудной жизненной ситуацией: помимо необходимости адаптации к условиям нового учебного заведения, нового региона, города или даже страны, к новым культурным и социальным нормам, языку, еще и начинается адаптация к самостоятельной жизни и стремительное взросление, вследствие необходимости принимать ответственность за свою жизнь, питание, проживание, управление деньгами и т. д. (Чернышев, 2016; Митин, 2010; Федотова, 2017, Уляева, 2019; Леонов, Хасан, 2019; Перикова, Бызова, Ловягина, 2019).

\section{Методы}

Дия изучения психологических предикторов адаптации мигрантов к трудной жизненной ситуации было проведено эмпирическое исследование, состоящее из нескольких этапов (с 2018 по 2020 гг., включая так называемый «период пандемии»). Эмпирическую базу исследования составили 380 человек - студенты высших учебных заведений Екатеринбурга и Томска в возрасте 18-22 с разным миграционным опытом: группа не-мигрантов - проходящих обучение по месту 
постоянного проживания (n=100), группы внутренних образовательных мигрантов из Томска и Екатеринбурга (n1=92, n2=90, соответственно), группа внешних образовательных мигрантов - граждан других государств (n=98).

В данной статье представим результаты одного из этапов исследования исследования сложных жизненных ситуаций, их типов и распространенности на разных группах образовательных мигрантов. Эта часть исследования проводилась с помощью авторской анкеты, которая разрабатывалась с участием фокус-групп молодежи городов Томска и Екатеринбурга. В нее вошли вопросы о переживании наиболее часто-встречающихся сложных жизненных ситуаций для образовательных мигрантов этих регионов. Часть из них отвечает их возрастным и учебным характеристикам, а часть возникла вследствие специфичности периода проведения исследования - периода пандемии коронавируса. Итоговый перечень составили сложные жизненные ситуации, связанные со следующими переживаниями: заболевания коронавирусом, переживания о здоровье близких, несостоявшаяся поездка (фиксирующая сложности передвижения), сложности с учебой, проблемы в личной жизни, бытовые сложности.

\section{Резудьтаты}

Исследование показало, что все респонденты в целом субъективно удовлетворены своей жизнью. Также, в целом респонденты скорее склонны испытывать Удовлетворенность тем, как прошел год, который модно стало считать субъективно-сложным и объективно-трудным (2020). Показатель общей удовлетворенности текущим годом дишь в некоторой степени отличается от общего показателя удовлетворенности жизнью в целом (напомним, оценивание производилось по 7-бальной шкале, и итоговые баллы 5,24 по сравнению с 4,36).

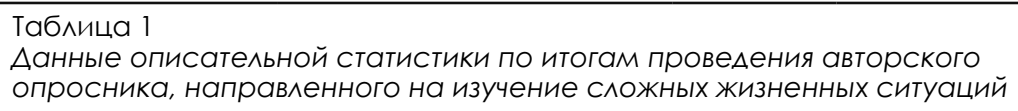

\section{Variable}

НасKO^ьKO

Вы в целОм уАОвАетворены Своей жизнью

Изменилось Аи восприятие Жизни в 2020 голу
Descriptive Statistics

Valid N Mean Std. Dev.




\begin{tabular}{|c|c|c|c|}
\hline $\begin{array}{l}\text { Таблица } 1 \\
\text { Аанные описател } \\
\text { опросника, напр }\end{array}$ & $\begin{array}{l}\text { стики по } \\
\text { са изуче }\end{array}$ & $\begin{array}{l}\text { жедени } \\
\text { жизне }\end{array}$ & $\begin{array}{l}\text { сского } \\
\text { итуаций }\end{array}$ \\
\hline & & Statistic & \\
\hline Variable & Valid N & Mean & Std. Dev. \\
\hline $\begin{array}{l}\text { Насколько Вы } \\
\text { УАовлетворены } \\
\text { Своей жизнью } \\
\text { в } 2020 \text { году }\end{array}$ & 380 & 4,36 & 1,561789 \\
\hline $\begin{array}{l}\text { Переживали ли } \\
\text { в этом голу: } \\
\text { Коронавирус }\end{array}$ & 380 & 0,26 & 0,443087 \\
\hline $\begin{array}{l}\text { Переживали ли } \\
\text { в этом гоАу: } \\
\text { Несостоявшаяся } \\
\text { поезАка }\end{array}$ & 380 & 0,28 & 0,453557 \\
\hline $\begin{array}{l}\text { Переживали ^и } \\
\text { в этом голу: } \\
\text { С^ожности } \\
\text { с учебой }\end{array}$ & 380 & 0,78 & 0,418452 \\
\hline $\begin{array}{l}\text { Переживали ли } \\
\text { в этом голу: } \\
\text { О зАоровье } \\
\text { родных }\end{array}$ & 380 & 0,74 & 0,443087 \\
\hline $\begin{array}{l}\text { Переживали ^и } \\
\text { в этом гоАу: } \\
\text { Бытовые } \\
\text { сложности }\end{array}$ & 380 & 0,60 & 0,494872 \\
\hline $\begin{array}{l}\text { Переживали ^и } \\
\text { в этом голу: } \\
\text { Проблемы } \\
\text { в ^ичной жизни }\end{array}$ & 380 & 0,36 & 0,484873 \\
\hline $\begin{array}{l}\text { Переживали ^и } \\
\text { в этом голу: } \\
\text { Ничего } \\
\text { особенного }\end{array}$ & 380 & 0,02 & 0,141421 \\
\hline $\begin{array}{l}\text { Насколько Вы } \\
\text { оцениваете } \\
\text { по 7-бальной }\end{array}$ & & & \\
\hline $\begin{array}{l}\text { Шкале } \\
\text { прошеАший гоА } \\
\text { как сложный } \\
\text { Аично А^я себя }\end{array}$ & 380 & 4,88 & 1,171777 \\
\hline
\end{tabular}


Были получены сведения о распространенности и популярности раздичных сложных жизненных ситуаций как на выборке в целом, так и на отдельных подгруппах образовательных мигрантов. Ниже представлены данные по частоте встречаемости и общей распространенности конкретных сложных жизненных ситуаций на разных выборках исследования.

Анализ типов и распространенности предложенных ситуаций показал следующее: часть сложных ситуаций распространены оказались лишь на 30 \% (заболевание коронавирусом, отмена несостоявшихся поездок, проблемы в дичной жизни), тогда как самыми «популярными» сложностями оказались сложности с учебой и переживания о здоровье близких (80\% по каждому показателю).

\begin{tabular}{|c|c|c|c|c|c|}
\hline ВиАы СЖС & $\begin{array}{c}\text { Hе- } \\
\text { мигранты }\end{array}$ & ОМ Екб & $\begin{array}{l}\text { OM } \\
\text { TOMCK }\end{array}$ & $\begin{array}{c}\text { Внеш. } \\
\text { Ом }\end{array}$ & $\begin{array}{l}\text { Итого } \\
\text { по СЖС }\end{array}$ \\
\hline $\begin{array}{l}\text { Болезнь (в т. ч. } \\
\text { коронавирус) }\end{array}$ & 25 & 23 & 27 & 30 & 105 \\
\hline $\begin{array}{l}\text { Несостоявшаяся } \\
\text { поезАка }\end{array}$ & 17 & 26 & 21 & 19 & 83 \\
\hline $\begin{array}{l}\text { С^ожности } \\
\text { с учебой }\end{array}$ & 98 & 89 & 77 & 90 & 354 \\
\hline $\begin{array}{l}\text { Переживания } \\
\text { о зАоровье } \\
\text { близких }\end{array}$ & 89 & 79 & 72 & 71 & 311 \\
\hline $\begin{array}{l}\text { Бытовые } \\
\text { сложности }\end{array}$ & 76 & 58 & 54 & 67 & 255 \\
\hline $\begin{array}{l}\text { Проблемы } \\
\text { в ^ичной жизни }\end{array}$ & 54 & 36 & 37 & 46 & 173 \\
\hline $\begin{array}{l}\text { Ничего } \\
\text { особенного }\end{array}$ & 1 & 1 & 0 & 3 & 5 \\
\hline $\begin{array}{l}\text { Итого } \\
\text { по группам }\end{array}$ & 360 & 312 & 288 & 326 & 1286 \\
\hline
\end{tabular}

Отметим, что изначально мы предполагади гораздо большее количество оценок субъективной сложности по пункту «Проблемы в личной жизни», однако, видимо, специфика событийной наподненности года сказалась и на этом, сместив фокус переживания в сторону других проблем. 
Далее вся группа респондентов была разделена на 2 подгруппы в зависимости от оценки степени сложности прошедшего года, при этом промежуточные показатели $(3,4,5)$ были исключены из анализа. В результате выяснилось, что 84 (22,1 \%) респондента оценивают год как скорее сложный, 18 (4,7\%)отказываются приписывать ему субъективную сложность. Сформированные подгруппы были проверены по показателям авторского опросника на достоверность раздичий.

Результаты дисперсионного анализа показали, что те респонденты, которые оценивают прошедший период, как сложный, достоверно в меньшей степени склонны испытывать удовлетворенность им и проявляют большую ригидность в отношении восприятия жизни в целом (не пересматривали свои взгдяды на жизнь). Данный результат, с одной стороны, заставдяет ставить вопрос о влиянии на восприятие мододых людей СМИ и других информационных ресурсов, а также «моды» считать период сложным. С другой стороны, становится иллюстрацией значимости психологического благополучия, как особого типа дичностного ресурса, который, проявляясь на уровне установок дичности и формирования готовности личности к действию или бездействию, изменению взглядов или сохранению их, может оказывать вдияние на общую удовлетворенность жизнью и особенности текущего психоэмоционального состояния.

Разделение всех участников на 2 подгруппы по оценке степени удовлетворенности прошедшим периодом (напомним, традиционно-в СМИ-именуемым, как сложный), дало иные результаты: те, кто удовлетворен прожитым годом, достоверно в большей степени удовлетворены и жизнью в целом, гораздо более гибкую позицию проявляют к своим мировоззренческим установкам и готовы пересматривать взгляды на жизнь, при этом достоверно в меньшей степени отмечают переживание сложностей в учебе.

Отметим, что в данном случае также промежуточные показатели $(5,4,3)$ были исключены из анадиза. В результате выяснилось, что 91 (23,9\%) респондентов удовлетворены своей жизнью в прошедший период, 53 (13,9\%) - скорее не удовдетворены своей жизнью в прошедший период.

Дополнительно на всем массиве был проведен корреляционный анализ, который показал наличие корреляционных связей между показателями субъективно-переживаемой удовлетворенности жизнью, удовлетворенности годом, изменением восприятия жизни (определенной мировоззренческой флексибильностью). В частности, было выявлено, что удовлетворенность жизнью в целом и последним годом имеют очень значимую корреляцию $(\mathrm{p}=0,00)$, также как и удовлетворенность годом оказалась связана с готовностью респондентов к изменениям и принятию этих изменений ( $=0,00)$. Тогда как удовлетворенность жизнью в целом также оказалась достаточно связана с переоценкой жизни респондентами $(\mathrm{p} \leq 0,05)$. 
Готовность к изменению своих позиций и мировоззренческих установок также обнаружила отрицательную корреляцию с оценкой прошедшего периода как сложного $(\mathrm{p} \leq 0,001)$, что из этих двух параметров стало причиной, а что следствием, вопрос дискуссионный и может быть подвергнут дополнитедьным проверкам в дальнейшем.

Были выявлены корреляции между склонностью оценивать год как сложный и сложностями с учебой $(\mathrm{p} \leq 0,05)$, переживаниями о здоровье родных $(\mathrm{p} \leq 0,05)$, что позволяет утверждать о том, что именно эти две сферы для наших респондентов оказались наиболее значимыми с точки зрения феномена «сложных жизненных ситуаций». В некотором смысле такой результат позволяет делать выводы об общем смещении ценностей современной обучающейся молодежи в условиях глобальных медицинских катастроф и пандемий с традиционно приписываемым им переживаний о личной жизни к переживаниям о здоровье близких. Сложности, связанные с учебой, в данном случае оказадись достаточно прогнозируемы и ожидаемы.

Удивительным, однако, оказался масштаб вдияния сложностей, связанных с учебой, на переживание удовлетворенности жизнью в целом и в текущем году. В обоих случаях были обнаружены очень высокие отрицательные корреляции $(\mathrm{p} \leq 0,005)$. Полагаем, что такой результат может быть связан с переживанием студентами обучения, как центральной сферы своего текущего жизнеосуществления.

При этом ситуация непосредственно самого заболевания (дичной болезни коронавирусом) не показала никаких значимых корреляционных связей ни с оценкой степени сложности прошедшего периода, ни с оценкой удовлетворенности им или пересмотром своих установок и принципов жизни, что заставдяет нас признать наличие субъективно разного отношения к такого типа жизненной ситуации у молодых людей, обучающихся в России, и предположить, что для многих из них она не является ни сложной, ни даже субъективно-значимой.

Кроме того, в анадиз был введен показатель миграции. Однако никаких корреляционных связей он с показателями субъективной оценки сложных жизненных ситуаций не дал, что позволяет утверждать, что в чистом виде принадлежность к группе «образовательных мигрантов» не вдияет однозначно ни на специфику восприятия сложных жизненных ситуаций молодыми дюдьми, ни на частоту и типичность переживания тех или иных сложных жизненных ситуаций.

Далее был проведен статистический анадиз данных авторского опросника сложных жизненных ситуаций с учетом выборок исследования. В частности, анализировались показатели студентов не-мигрантов, внутренних образовательных мигрантов и студентов из других государств.

Сперва мы подвергди дисперсионному анадизу показатели групп немигрантов и внутренних мигрантов. 
Данные дисперсионного анализа показали, что не-мигранты достоверно более удовлетворены прошедшим годом ( $\mathrm{p} \leq 0,01)$, оказались более готовыми менять свое восприятие жизни $(\mathrm{p}=0,00)$ и в гораздо меньшей степени отмечают испытываемые сложности с учебой ( $\mathrm{p} \leq 0,05)$. Этот результат возвращает нас к ранее уже высказанным предположениям: находясь в родной среде, привычных условиях, под заботой близких, в меньшей степени наделяя избыточной важностью обучение, так как оно для них, возможно, тодько обучение, а не попытка смены места жительства и дальнейшего развития.

Мы подвергди дисперсионному анадизу показатели групп внутренних мигрантов и внешних образовательных мигрантов.

Результаты показывают, что внешние образовательные мигранты гораздо более готовы менять восприятие жизни $(\mathrm{p} \leq 0,05)$ и в меньшей степени отмечают в анкетах наличие сложностей с учебой, чем внутренние образовательные мигранты ( $\leq 00,05)$. Это позволяет утверждать, что, будучи в большей степени адаптивными, испытывающими постоянные изменения своих взглядов и мировосприятия даже от просто обучения в другой стране и культуре, они изначально более открыты новому, что в целом согласуется с представлениями о личностных особенностях иностранных студентов (Митин, 2010; Покровская и д. р., 2014). Меньшая значимость для иностранных студентов сложностей с учебой может быть объяснено посредством двух предположений, каждое из которых, впрочем, требует проверки. Во-первых, как правило, в эту группу - внешних образовательных мигрантов - включены студенты, которые уже не первый год обучаются в другой стране и уже имели самый разнообразный опыт решения сложностей с процессом своего обучения, на фоне которых, возможно, сложности последнего года оказались менее заметными (а многие из иностранных студентов так и не смогли приехать в страну обучения, дибо же наоборот выбрали проживание в ней без возвращения домой в течение года и издишнего пересечения границ, таким образом минимизировади себе стрессы, в какой-то степени «выбрав среду»). Во-вторых, среди внешних образовательных мигрантов, как мы писади, есть те, кто планирует после обучения оставаться в России, но при этом настолько плотной связи между обучением в конкретном вузе и возможностью жить там, где хочется, у них нет, в силу более выраженного миграционного опыта. Еще раз отметим, оба данных предположения требуют дополнительных проверок и уточнений.

\section{Обсуждение резудьтатов}

Результаты проведенного этапа исследования следует сравнить с результатами многих зарубежных исследований, изучающих особенности адаптации образовательных мигрантов к новой образовательной и социально-психологической среде. В исследовании Ю. Цхай, Х. Ду изучалось влияние пандемии Ковид-19 
на психическое здоровье китайских студентов, обучающихся за рубежом. Было показано, что беспокойство о здоровье своих близких дополняется информацией в СМИ, содержащей уничижительные заголовки, стереотипные суждения и предубеждения об их этнической группе и о роли Китая в распространении Ковид-19. Все это приводит увеличению уровня стресса, тревожности и страхов среди китайских студентов-мигрантов (Y. Zhai, \& X. Du, 2020). Психологическое благополучие образовательных мигрантов в период пандемии также является предметом исследований зарубежных исследователей: финансовая нестабильность, непредсказуемость будущего / карьеры и воздействие средств массовой информации были описаны как общие стресс-факторы, которые вызывают снижение уровня психологического благополучия и снижают экономическую стабильность. COVID-19, карантин, ограничительные меры (в том числе и возможность свободно перемещаться по стране и миру) и вынужденная самоизоляция в первую очередь ослабляют психическое здоровье студентов университетов (López et all, 2020; Kocjan., Kavčič, \& Avsec, 2021; Li, Hafeez, \& Zaheer, 2021; Curșeu, Coman, Panchenko, Fodor, \& Rațiu, 2021). Результаты приведенных исследований указывают на особенности переживания иностранными студентами ситуации пандемии, что не подтверждается результатами нашего исследования, где достоверных раздичий в показателях переживаний раздичных сложных ситуаций и общей степени удовлетворенности между показателями групп студентов из иностранных государств и не-мигрантов обнаружено не было.

\section{Выводы}

Таким образом, полученные результаты показали, что самыми «популярными» и значимыми с точки зрения феномена «сложных жизненных ситуаций» для респондентов оказались сложности с учебой и переживания о здоровье близких.

Корреляционный анализ выявил значимые положительные связи между субъективно-переживаемой удовлетворенностью жизнью, удовлетворенностью годом (оцениваемым периодом) и изменением восприятия жизни (определенной мировоззренческой флексибильностью). Оценка прошедшего периода как сложного обнаружила отрицательную корреляцию с готовностью к изменению своих позиций и мировоззренческих установок. Обнаружено сильное негативное влияние переживаний ситуаций, связанных с проблемами в учебе, на общую оценку удовлетворенности как жизнью в целом, так и оцениваемым периодом.

При этом ситуация самого заболевания (дичной болезни коронавирусом) и показатель миграции не дали никаких значимых корреляционных связей ни с каким другим показателем. Это позволяет утверждать, что ситуация заболевания коронавирусом для многих молодых людей не является сложной, а принадлежность к группе «образовательных мигрантов» не вдияет однозначно 
на специфику восприятия сложных жизненных ситуаций мододыми людьми, их частоту и типичность переживания.

Сравнение восприятия сложных жизненных ситуаций на разных группах образовательных мигрантов показало ряд специфичных отличий в переживаниях между группами: большую удовлетворенность прошедшим годом у студентов, обучающихся по месту проживания, большую мировоззренческую флексибильность у не-мигрантов и внешних образовательных мигрантов, а также большую значимость и субъективно-переживаемую сложность проблем с учебой для внутренних мигрантов.

\section{Дитература}

Апанович М. Ю. Образовательная миграция в России: точки развития // Вестник науки и образования. 2015. №9(11). С. 79-82.

Игнатовский А. С., Штро Р. С. Ретроспективная оценка факторов профессионального самоопределения студентов российских ВУЗов // Тенденции науки и образования в современном мире. 2019. №. 48-2. С. 16-20.

Иеонов Н. И., Хасан Ф. Х. Копинг-ресурсы иностранных студентов в трудной жизненной ситуации // Вестник Удмуртского университета. Серия «Философия. Психология. Педагогика». 2019. № 29(3). С. 291-297.

Митин Д. Н. Образовательная (учебная) миграция: понятие, проблемы и пути решения // Вестник РУДН. Серия: Политология. 2010. № 3. С. 123-134.

Перикова Е. И., Бъззова В. М., Ловягина А. Е. Психическая саморегуляция студентов в трудных жизненных ситуациях // Вестник Вятского государственного университета. 2019. №2. С. 99-106.

Покровская Е. М., Смольникова А. В., Ларионова А. В. Проблема создания модели социокультурной интеграции иностранных студентов // Психология, социология и педагогика. 2014. № 11(38). С. 124-127.

Рязанцев С. В. Мировой рынок труда и международная миграция. М.: Экономика, 2010. 303 с.

Трофимов Е. А., Трофимова Т. И. Особенности учебной миграции в условиях глобализации // Тенденции и проблемы в экономике России: теоретические и практические аспекты: материалы Всероссийской научно-практической конференции. Иркутск: Изд-во БГУ, 2017. С. 219-224.

Уляева А. Г. Психологические ресурсы: понятие, виды, функции, роль в самореализации дичности // Живая психология. 2019. Т. 6, № 4(24). С. 255-265.

Федотова В. А. Ценности россиян в контексте возрастных раздичий // Вестник Пермского университета. Философия. Психология. Социология. - 2017. №1. С. 78-86.

Чернышев К. А. Образование как фактор миграционной подвижности: опыт оценки и принятия управленческих решений на региональном уровне // Вопросы управления. 2014. № 6(12). С. 172-178. 
Шnет E. Н. Учебная миграция как инструмент дия подготовки студентов вузов с использованием практик зарубежной образовательной системы // Научно-педагогическое обозрение. 2015. №1(7). С. 30-37.

Curșeu P. L., Coman A. D., Panchenko A., Fodor O. C., Rațiu L. Death anxiety, death reflection and interpersonal communication as predictors of social distance towards people infected with COVID 19. Current psychology. 2021. DOI: $10.1007 /$ s12144-020-01171-8

Kocjan G. Z., Kavčič T., Avsec A. Resilience matters: Explaining the association between personality and psychological functioning during the COVID-19 pandemic // International Journal of Clinical and Health Psychology. 2021. Vol. 21, Issue 1. 100198. DOI: $10.1016 /$ j.ijchp.2020.08.002

Li H., Hafeez H., Zaheer M. A. COVID-19 and Pretentious Psychological WellBeing of Students: A Threat to Educational Sustainability. Frontiers in psychology. 2021. Vol. 11. 4034. DOI: $10.3389 /$ fpsyg. 2020.628003

López J., Perez-Rojo G., Noriega C., Carretero I., Velasco C., Martinez-Huertas J. A., López-Frutos P., Galarraga L. Psychological well-being among older adults during the COVID-19 outbreak: a comparative study of the young-old and the old-old adults // International Psychogeriatrics. 2020. Vol. 32(11). P. 1365-1370. DOI: 10.1017/ $\underline{\mathrm{S} 1041610220000964}$

Zhai Y., Du X. Mental health care for international Chinese students affected by the COVID-19 outbreak. The lancet Psychiatry. 2020. Vol. 7, Issue 4, e22. DOI: 10.1016/S2215-0366(20)30089-4

\section{References}

Apanovich, M. YU. (2015). Educational migration in Russia: points of development. Vestnik of Science and Education, 9(11), 79-82. (in Russ.).

Chernyshev, K. A. (2014). Education as a factor of migration mobility: experience in assessing and making managerial decisions at the regional level. Management issues, 6(12), 172-178. (in Russ.).

Curșeu, P. L., Coman, A. D., Panchenko, A., Fodor, O. C., \& Rațiu, L. (2021). Death anxiety, death reflection and interpersonal communication as predictors of social distance towards people infected with COVID 19. Current psychology. DOI: $10.1007 / \mathrm{s} 12144-020-01171-8$

Fedotova, V. A. (2017). Values of Russians in the Context of Age Differences. Vestnik of Perm University. Philosophy. Psychology. Sociology, 1, 78-86. (in Russ.).

Ignatovskij, A. S., \& SHtro, R. S. (2019). Retrospective assessment of the factors of professional self-determination of students of Russian universities. Trends in science and education in the modern world, 48-2, 16-20. (in Russ.).

Kocjan, G. Z., Kavčič, T., \& Avsec, A. (2021). Resilience matters: Explaining the association between personality and psychological functioning during the COVID-19 
pandemic. International Journal of Clinical and Health Psychology, 21(1), 100198. DOI: 10.1016/j.ijchp.2020.08.002

Leonov, N. I., \& Hasan, F. H. (2019). Coping resources of international students in difficult life situations. Vestnik of Udmurt University. Series "Philosophy. Psychology. Pedagogy", 29(3), 291-297. (in Russ.).

Li, H., Hafeez, H., \& Zaheer, M. A. (2021). COVID-19 and Pretentious Psychological Well-Being of Students: A Threat to Educational Sustainability. Frontiers in psychology, 11, 4034. DOI: 10.3389/fpsyg.2020.628003

López, J., Perez-Rojo, G., Noriega, C., Carretero, I., Velasco, C., Martinez-Huertas, J. A., López-Frutos, P., \& Galarraga, L. (2020). Psychological well-being among older adults during the COVID-19 outbreak: a comparative study of the young-old and the old-old adults. International Psychogeriatrics, 32(11), 1365-1370. DOI: $10.1017 /$ $\underline{\mathrm{S} 1041610220000964}$

Mitin, D. N. (2010). Educational migration: concept, problems, and solutions. Vestnik of Peoples' Friendship University of Russia. Series: Political Science, 3, 123-134. (in Russ.).

Perikova, E. I., Byzova, V. M., \& Lovyagina, A. E. (2019). Mental self-regulation of students in difficult life situations. Vestnik of Vyatka State University, 2, 99-106. (in Russ.).

Pokrovskaya, E. M., Smol'nikova, L. V., \& Larionova, A. V. (2014). The issue of creating a model of socio-cultural integration of foreign students. Psychology, Sociology and Pedagogy, 11(38), 124-127. (in Russ.).

Ryazancev, S. V. (2010). Global labor market and international migration. Moscow: Ekonomika. (in Russ.).

Shpet, E. N. (2015). Educational migration as a tool for training university students using the practices of the foreign educational system. Pedagogical Review, 1(7), 30-37. (in Russ.).

Trofimov, E. A., \& Trofimova, T. I. (2017). Features of educational migration in the context of globalization. In Kurganskij, C. A. (ed.) Trends and problems in the Russian economy: theoretical and practical aspects. Proceedings of the All-Russian scientific-practical conference (pp. 219-224). Irkutsk: Publishing House of the Buryat State University. (in Russ.).

Ulyaeva, L. G. (2019). Psychological resources: concept, types, functions, role in personal self-realization. ZHivaya psihologiya, 6-4(24), 255-265. (in Russ.).

Zhai, Y., \& Du, X. (2020). Mental health care for international Chinese students affected by the COVID-19 outbreak. The lancet Psychiatry, 7(4), e22. DOI: $10.1016 /$ $\underline{\text { S2215-0366(20)30089-4 }}$ 